\title{
Environmental performance evaluation of suppliers: A hybrid fuzzy multi-criteria decision approach
}

\author{
${ }^{1 *}$ G. Tuzkaya; ${ }^{2}$ A. Ozgen; ${ }^{1} D$. Ozgen; ${ }^{1} U$. R. Tuzkaya \\ ${ }^{1}$ Department of Industrial Engineering, Yildiz Technical University, Yildiz, Istanbul, Turkey \\ ${ }^{2}$ Department of Industrial Engineering, Okan University, Akfirat, Tuzla, Istanbul, Turkey \\ Received 6 March 2009; $\quad$ revised 21 April 2009; accepted 20 May 2009; available online 1 June 2009
}

\begin{abstract}
Increasing environmental problems enforce companies to be more environmental responsible. A company's environmental performance is not only related to the company's inner environmental efforts, but also it is affected by the suppliers' environmental performance and image. As a stakeholder of the company, a supplier with bad environmental image affects badly the company's environmental image. Also, raw materials and semi-finished products supplied from out of the company recourses- suppliers- affects the products environmental features such as life cycle, re-usability, re-manufacturability, hazardous substances, etc. Considering these direct and indirect effects, managers should also consider environmental performances of their suppliers in their supplier evaluation process. In this paper, a methodology for the evaluation of suppliers' environmental performances is proposed. In this methodology, a hybrid Fuzzy-Analytic Network Process and Fuzzy-Preference Ranking Organization METHod for Enrichment Evaluations approach is utilized. Additionally, a numerical example is given to foster the better understanding of the methodology and the obtained results are analyzed with sensitivity analyses.
\end{abstract}

Keywords: Decision-making; Environmental criteria; Fuzzy sets; Green supply chain

\section{INTRODUCTION}

Supply chain management (SCM) is the integration and management of supply chain organizations and activities through cooperative organizational relationships, effective business processes and high levels of information sharing to create high-performing value systems that provide member organizations a sustainable competitive advantage (Handfield and Nichols, 2004). Many academicians and practitioners are utilized from operations management techniques to deal with optimizing internal processes of firms. These optimization efforts are both applied for a particular process or the entire set of processes that provide value to the end customer. The entire set of processes includes those that are both internal and external to the firm. This perspective is often referred to as supply chain management and is a potentially powerful way for companies to ensure that customers are receiving the most value for their money.

Arranging all activities associated with moving goods from the raw material stage to the end user constitutes the whole supply chain management

$\triangle$ *Corresponding Author Email: gtuzkaya@yildiz.edu.tr

Tel.: +90 2123832 919; Fax: +90 2123832919 concept. These stages include systems management, sourcing and procurement, production scheduling, order processing, inventory management, warehousing and customer service. For achieving sustainable competitive advantage beside a successful supply chain management, these activities have to be coordinated and integrated. All these stages have to be considered one by one in the optimization efforts. Besides coordinating interior stages and factors together, companies nowadays have to consider other issues that become important for the sustainability of business and management. One of these issues is environmental factors. Legitimate and social responsibilities bring pressure on the attainment of good environmental practices. One of the important topics that are considered under environmental issues is pollution. Manufacturers and firms are paying attention to the environmental benign efforts in their products/services with less packaging materials and more sensitive to the other pollution factors. The most effective way to reach this objective is constitute environmental policy in each step of the supply chain management stages. The most important stage that 
environmental factors could be handled as activities related to the purchasing function. This calls the attention to the role of the environmental dimension in suppliers and buyers relationships in supply chain. Noci (1997) has defined the benefits of this cooperation in four items as; reducing the quantity of supplied components with low environmental performance, effective cost controlling of "green" products of suppliers, reducing the company's response time to the expectations of green market and avoiding problems associated with the company's "green” image. Combining environmental issues with supply chain management necessitates integrating environmental management issues such as life cycle analysis, waste management, etc. with supply chain management practices such as vendor assessment, total quality management, lean supply and collaborative practices (Lamming and Hampson, 1996).

This integration brings green supply chain management or environmentally conscious supply chain management. In literature, several studies have realized in this area such as Handfield et al. (2002); Humphreys et al. (2003); Nakashima et al. (2006); Ofori (2000); Sarkis (1998).

Green supply chain management is a structure that requires successful coordination, integration and management across members (enterprises) in the supply chain that includes raw material suppliers, manufacturers, distributors, users and recyclers. These efforts for collaborative relationships are necessary for environmental betterment. For this reason, a variety of approaches have developed for evaluating the companies' relationships with their suppliers to improve the environmental performance of the final products. These approaches have used methods such as the categorical method, the weighted-point method, the matrix approach, Vendor Profile Analysis (VPA), and the Analytic Hierarchy Process (AHP). These methods have assisted managers to constitute systematic analyses on the basis of criteria such as quality, cost issues, delivery and flexibility.

Based on the reasons described above, this study has three main objectives. Firstly, to identify the environmental criteria which influence a company's purchasing decisions. Secondly, to develop a framework of the supplier selection process which incorporates environmental performance and finally use the framework to develop an environmental decision support system to illustrate that how proposed model can assist in the evaluation of suppliers environmental performance. It is emphasized that the findings should help firms enhance their competitive position in the market and in the presence of community by considering environmental factors in the evaluation phase of their suppliers. To this end, an integrated Fuzzy-Analytic Network Process (ANP) and FuzzyPreference Ranking Organization METHod for Enrichment Evaluations (PROMETHEE) methodology is proposed. ANP method was proposed by Saaty and Takiawz (1986) and it is an extension of AHP. In reality, the elements within the hierarchy of various criteria are often interdependent, but low-level elements may dominate high-level ones. A feedback relationship also exists in the process, thus, this structure resembles a network system (Lin, 2009). In order to solve this kind of imprecise and to cope with the complex network type of criteria relations in a multi-criteria decisionmaking (MCDM) problem, fuzzy ANP(F-ANP) method can be utilized.

Unlike other ranking methods in the literature, different preference functions can be defined for criteria in PROMETHEE method (Dagdeviren, 2008). It is a ranking method quite simple in conception and application compared to other methods for MCDM. It is well adapted to problems where a finite number of alternative actions are to be ranked considering several, sometimes conflicting criteria (Bilsel et al., 2006). According to Ulengin et al. (2001), some of the advantages of PROMETHEE are: (i) PROMETHEE is a user friendly outranking method, (ii) it has been successfully applied to real life planning problems and (iii) PROMETHEE I and PROMETHEE II allow both partial and total ranking of the alternatives while still satisfying simplicity. In this paper, for treating the imprecision which is constituted by vague situations the "extension of the PROMETHEE method in a fuzzy environment" (F-PROMETHEE) is integrated with F-ANP. The research work explained in the paper has been done in Istanbul, Turkey, during January-March 2009.

\section{MATERIALS AND METHODS}

\section{Mathematical background}

Fuzzy sets

Some definitions of fuzzy sets related to this study are given as follows:

Definition 1. A fuzzy set $\tilde{A}$ in a universe of discourse $X$ is characterized by membership function $\mu_{\tilde{A}}(X)$, which associates with each element $x$ in $X$, a real number in 
the interval $[0,1]$. The function $\mu_{\hat{A}}(X)$ is termed the grade of membership of $x$ in $\tilde{A}$ (Chen, 2001).

Definition 2. A triangular fuzzy number can be defined as $a$ triplet $\left(a^{l}, a^{m}, a^{u}\right)$; the membership function of the fuzzy number $\tilde{A}$ is defined as below (Wang and Chang, 2007):

$$
f \tilde{A}^{(x)}=\left\{\begin{array}{ll}
0, & x<a^{l}, \\
\left(x-a^{l}\right) /\left(a^{m}-a^{l}\right), & a^{l} \leq x \leq a^{m}, \\
\left(a^{u}-x\right) /\left(a^{u}-a^{m}\right), & a^{m} \leq x \leq a^{u} \\
0, & x>a^{u} .
\end{array}\right\}
$$

Let $\tilde{A}$ and $\tilde{B}$ be two triangular fuzzy numbers parameterized by the triplets $\left(a^{l}, a^{m}, a^{u}\right)$ and $\left(b^{l}, b^{m}, b^{u}\right)$, respectively; then the operational laws of these two triangular fuzzy numbers are as follows (Wang and Chang, 2007):

$$
\begin{aligned}
& \tilde{A}(+) \widetilde{B}=\left(a^{l}, a^{m}, a^{u}\right) \oplus\left(b^{l}, b^{m}, b^{u}\right) \\
& =\left(a^{l}+b^{l}, a^{m}+b^{m}, a^{u}+b^{u}\right) \\
& \tilde{A}(-) \tilde{B}=\left(a^{l}, a^{m}, a^{u}\right)-\left(b^{l}, b^{m}, b^{u}\right) \\
& =\left(a^{l}-b^{u}, a^{m}-b^{m}, a^{u}-b^{l}\right)
\end{aligned}
$$

$$
\begin{aligned}
& \sim(x) B \cong\left(a^{l}, a^{m}, a^{u}\right) \otimes\left(b^{l}, b^{m}, b^{u}\right) \\
& =\left(a^{l} b^{l}, a^{m} b^{m}, a^{u} b^{u}\right)
\end{aligned}
$$

$$
\begin{aligned}
& \tilde{A}(\div) \tilde{B} \cong\left(a^{l}, a^{m}, a^{u}\right) \div\left(b^{l}, b^{m}, b^{u}\right) \\
& =\left(\frac{a^{l}}{b^{l}}, \frac{a^{m}}{b^{m}}, \frac{a^{u}}{b^{u}}\right)
\end{aligned}
$$$$
k \tilde{A}=\left(k a^{l}, k a^{m}, k a^{u}\right)
$$

$(\tilde{A})^{-1}=\left(\frac{1}{a^{u}}, \frac{1}{a^{m}}, \frac{1}{a^{l}}\right)$

Definition 3. A linguistic variable is a variable whose values are linguistic terms (Chen, 2001).

The concept of linguistic variable is very useful in dealing with situations which are too complex or too ill-defined to be reasonably described in conventional quantitative expressions. These linguistic variables can also be represented by fuzzy numbers (Chen, 2001).

\section{ANP and F-ANP}

ANP is a comprehensive decision-making technique that has the capability to include all the relevant criteria which have some bearing on arriving at a decision. Analytic hierarchy process serves as the starting point of ANP (Jharkharia and Shankar, 2007). The ANP provides a general framework to deal with decisions without making assumptions about the interdependence of the elements within a level. In fact, ANP uses a network without needing to specify levels as in a hierarchy. Influence is a central concept in the ANP. The ANP is a useful tool for prediction and for representing a variety of competitors with their surmised interactions and their relative strengths to wield influence in making a decision. The ANP is a coupling of two parts; the first consists of control hierarchy or a network of criteria and sub-criteria that controls the interactions, while the second is a network of influences among the elements and clusters (Saaty, 1999; Tuzkaya et al., 2008; Tuzkaya and Gulsun, 2008). In some cases, if there is vagueness for the decision problem, utilizing fuzzy sets is a useful way. For this reason, in this study, the usage of the fuzzy version of ANP is preferred. In the literature, Ayag and Ozdemir (2006), Büyükozkan et al. (2004), Promentilla et al. (2008), Tuzkaya and Onut (2008) are the examples of the works which are utilized from the F-ANP approach. In the F-ANP, to evaluate the decision makers preferences, pair-wise comparisons are structured using triangular fuzzy numbers $\left(a^{l}, a^{m}, a^{u}\right)$. The $m x n$ fuzzy matrix can be given as in Eq. 8. The element $a_{m n}$ represents the comparison of the component $m$ (row element) with component $n$ (column element). If $\tilde{A}$ is a pairwise comparison matrix (Eq. 8), it is assumed that the reciprocal and the reciprocal value, i.e. $1 / a_{m n}$, is assigned to the element $a_{m n}$ (Tuzkaya and Onut, 2008): 


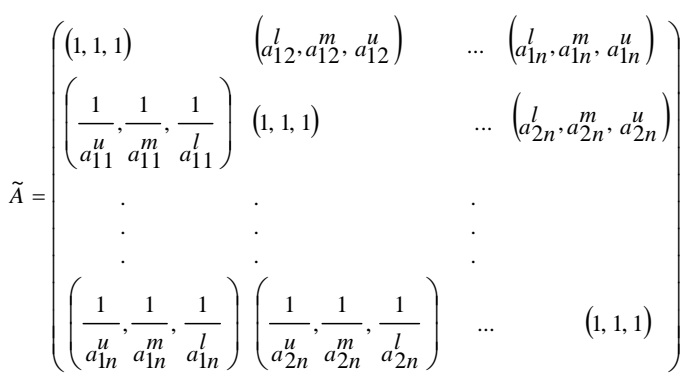

$\tilde{A}$ is also a triangular, fuzzy, pairwise comparison matrix. There are several methods for getting estimates for the fuzzy priorities, $\tilde{w}_{i}$, where and $i=1,2, \ldots, n$, from the judgment matrix, $\tilde{A}$, which approximates the fuzzy ratios $\tilde{a}_{i j}$, so that $\tilde{a}_{i j} \approx \tilde{w}_{i} / \tilde{w}_{j}$. One of these methods, the logarithmic least-squares method, is used in this study since it is a most-used and effective method. The triangular fuzzy weights representing the relative importance of the criteria, the feedback of the criteria and the alternatives according to individual criteria is calculated by this method. The logarithmic leastsquares method for calculating triangular fuzzy weights can be given as follows (Tuzkaya and Onut, 2008):

$\tilde{w}_{i}=\left(w_{i}^{l}, w_{i}^{m}, w_{i}^{u}\right),{ }_{k=1,2}, \ldots, n$

Where,

$$
w_{i}^{S}=\frac{\left(\Pi_{j=1}^{n} a_{i j}^{S}\right)^{1 / n}}{\sum_{k=1}^{n}\left(\prod_{j=1}^{n} a_{k j}^{m}\right)^{1 / n}}, s \in\{l, m, u\}
$$

The alternatives are evaluated as previously expressed. Following this step, for converting the weights of the alternatives to crisp numbers, three approaches are utilized: Chang's extent analysis (1996) method, Center of Area (COA) method (Sugeno, 1985) and Yager Index (Yager, 1981) are utilized. The steps of Chang's extent analysis approach, by integrating the improvements of Zhu et al. (1999) are as follows: Let $X$ $=\left\{x_{1}, x_{2}, \ldots, x_{n}\right\}$ be an object set and $U=\left\{u_{1}, u_{2}, \ldots, u_{m}\right\}$ be a goal set. Each object is taken and extent analysis for each goal, $g_{i}$, is performed, respectively. Therefore, $m$ extent analysis values for each object can be obtained, with the following signs (Büyükozkan et al., 2004):

$M_{g_{i}}^{1}, M_{g_{i}}^{2}, \ldots, M_{g_{i}}^{m} \quad i=1,2, \ldots, n$
Where all the $M_{g_{i}}^{j}(j=1,2, \ldots, m)$ are triangular fuzzy numbers (TFNs).

The steps of Chang's extent analysis can be given as follows:

Step 1. The value of fuzzy synthetic extent with respect to the ith object is defined as

$S_{i}=\sum_{j=1}^{m} M_{g_{i}}^{j} \otimes\left[\sum_{i=1}^{n} \sum_{j=1}^{m} M_{g_{i}}^{j}\right]^{-1}$

To obtain $\sum_{j=1}^{m} M_{g_{i}}^{j}$, perform the fuzzy addition operation of $m$ extent analysis value for a particular matrix such that:

$\sum_{j=1}^{m} M_{g_{i}}^{j}=\left(\sum_{j=1}^{m} l_{j}, \sum_{j=1}^{m} m_{j}, \sum_{j=1}^{m} u_{j}\right)$

And to obtain $\left[\sum_{i=1}^{n} \sum_{j=1}^{m} M_{g_{i}}^{j}\right]^{-1}$, perform the fuzzy edition operation of $M_{g_{i}}^{j}(j=1,2, \ldots, m)$ values such that

$\sum_{i=1}^{n} \sum_{j=1}^{m} M_{g_{i}}^{j}=\left(\sum_{i=1}^{n} l_{i}, \sum_{i=1}^{n} m_{i}, \sum_{i=1}^{n} u_{i}\right)$

And then compute the inverse of the vector in Eq. 14 such that:

$\left[\sum_{i=1}^{n} \sum_{j=1}^{m} M_{g_{i}}^{j}\right]^{-1}=\left(\frac{1}{\sum_{i=1}^{n} u_{i}}, \frac{1}{\sum_{i=1}^{n} m_{i}}, \frac{1}{\sum_{i=1}^{n} l_{i}}\right)$

Step 2. The degree of possibility of $M_{2}=\left(l_{2}, m_{2}, u_{2}\right) \geq M_{1}=\left(l_{1}, m_{1}, u_{1}\right)$ is defined as

$V\left(M_{2} \geq M_{1}\right)=\sup _{y \geq x}\left[\min \left(\mu_{M_{1}}(x), \mu_{M_{2}}(y)\right)\right]$

And can be equivalently expressed as follows:

$V\left(M_{2} \geq M_{1}\right)=\operatorname{hgt}\left(M_{1} \cap M_{2}\right)=\mu_{M_{2}}(d)=$ $\left\{\begin{array}{cl}1, & \text { if } m_{2} \geq m_{1}, \\ 0, & \text { if } l_{1} \geq u_{2}, \\ \frac{l_{1}-u_{2}}{\left(m_{2}-u_{2}\right)-\left(m_{1}-l_{1}\right)} & \text { otherwise }\end{array}\right.$ 
Where $d$ is the ordinate of the highest intersection point $D$ between, $\mu_{M_{1}}$ and $\mu_{M_{2}}$ to compare $M_{1}$ and $M_{2}$, both the values of $V\left(M_{1} \geq M_{2}\right)$ and $V\left(M_{2} \geq M_{1}\right)$. are needed.

Step 3. The degree possibility for a convex fuzzy number to be greater than $k$ convex fuzzy numbers $M_{i}(i=1,2, \ldots, k)$ can be defined by

$$
\begin{aligned}
& V\left(M \geq M_{1}, M_{2} \ldots, M_{k}\right)=V\left[\begin{array}{l}
\left(M \geq M_{1}\right) \text { and }\left(M \geq M_{2}\right) \\
\text { and ...and }\left(M \geq M_{k}\right)
\end{array}\right] \\
& =\min V\left(M \geq M_{i}\right), i=1,2,3, \ldots, k .
\end{aligned}
$$

Assume that:

$d^{\prime}\left(A_{i}\right)=\min V\left(S_{i} \geq S_{k}\right)$

For; $k=1,2, \ldots, n$ and $k \neq i$. Then the weight vector is given by:

$$
W^{\prime}=\left(d^{\prime}\left(A_{1}\right), d^{\prime}\left(A_{2}\right), \ldots, d^{\prime}\left(A_{n}\right)\right)^{\mathrm{T}},
$$

Where $A_{i}(i=1,2, \ldots, n)$ are $n$ elements.

Step 4. Via normalization, the normalized weight vectors are

$W=\left(d\left(A_{1}\right), d\left(A_{2}\right), \ldots, d\left(A_{n}\right)\right)^{\mathrm{T}}$,

Where $W$ is a nonfuzzy number.

The normalized weight vector can also be obtained by some other methods in the literature. One of these is Center of Area (COA) method. This technique was developed by Sugeno in 1985 (Sugeno, 1985). This is also one of the most commonly used techniques. COA technique can be expressed as:

$$
x^{*}=\frac{\int \mu_{i}(x) x d x}{\int \mu_{i}(x) d x}
$$

Where, $x^{*}$ is the defuzzified output, $\mu_{i}(x)$ is the aggregated membership function and $x$ is the output variable. The only disadvantage of this method is that it is computationally difficult for complex membership functions.

Another defuzzification method is Yager index (Yager, 1981) and it is simply calculated by Eq. 23:

$$
\widetilde{F}=(n-a, n, n+b)=(3 n-a+b) / 3
$$

\section{PROMETHEE and F-PROMETHEE}

PROMETHEE (Preference Ranking Organization METHod for Enrichment Evaluations) is an outranking method which initial references are prepared by Brans and Vincle (1985) and Brans et al. (1986). It is a quite simple ranking method in conception and application compared with other methods used for multi-criteria analysis. It is well adapted to the problems where a finite set of alternatives are to be ranked according to several, sometimes conflicting criteria (Albadvi et al., 2007; Dagdeviren, 2008). The evaluation is the starting point of PROMETHEE method. In this phase, alternatives are evaluated with respect to different criteria. These evaluations involve essentially numerical data. The implementation of PROMETHEE requires two additional types of information, namely (Macharis et al., 2004):

- Information on the relative importance (i.e. the weights) of the criteria considered,

- Information on the decision-makers' preference function, which he/she uses when comparing the contribution of the alternatives in terms of each separate criterion.

The basic steps of the PROMETHEE algorithm can be outlined as follows (Brans et al., 1986; Geldermann et al., 2000):

Step 1. Specify a generalized preference function $p_{j}(d)$ for each criterion $j$. (Fig. 1).

Step 2. Define a vector containing the weights, which are a measure for the relative importance of each criterion, $w^{T}=\left[w_{1}, \ldots, w_{k}\right]$. If all the criteria are of the same importance in the opinion of the decision maker, all weights can be taken as being equal. The normalization of the weights, $\sum_{k=1}^{K} w_{k}=1$, is not necessarily required.

Step 3. Define for all the alternatives $a_{t}, a_{t^{\prime}} \in A$ the outranking relation $\pi$ :

$$
\pi:\left\{\begin{array}{l}
A x A \rightarrow[0,1] \\
\pi\left(a t, a t^{\prime}\right)=\sum_{k=1}^{K} w k \cdot\left(p_{k}\left(f_{k}(a t)-f_{k}\left(a t^{\prime}\right)\right)\right.
\end{array}\right.
$$

The preference index $\pi\left(a_{t}, a_{t^{\prime}}\right)$ is a measure for the intensity of preference of the decision maker for an alternative $a_{t}$ in comparison with an alternative $a_{t}$ for the simultaneous consideration of all criteria. It is basically a weighted average of the preference functions $p_{k}(d)$ and can be represented as a valued outranking graph. 
Step 4. As a measure for the strength of alternatives $a_{t} \in A$, the leaving flow is calculated:

$$
\Phi^{+}(a t)=\frac{1}{T-1} \cdot \sum_{\substack{t^{\prime}=1 \\ t^{\prime} \neq t}}^{n} \pi\left(a t, a t^{\prime}\right)
$$

The leaving flow is the sum of the values of the arcs which leave node $a_{t}$ and therefore yields a measure of the "outranking character" of $a_{t}$.

Step 5. As a measure for the weakness of the alternatives $a_{t} \in A$, the entering flow is calculated, measuring the "outranked character" of $a_{t}$ (analogously to the leaving flow):

$$
\left.\Phi^{-}(a t)=\frac{1}{T-1} \cdot \sum_{\substack{t^{\prime} \\ t^{\prime} \\ t^{\prime}}}^{n} \pi\left(a t^{\prime}, a t\right)\right)
$$

Step 6. A graphical evaluation of the outranking relation is derived: Basically, the higher the leaving flow and the lower the entering flow, the better the action. This result is graphically represented by a partial preorder (PROMETHEE I) or a complete preorder (PROMETHEE II).

In PROMETHEE I, alternative $a_{t}$ is preferred to alternative $a_{t},\left(a_{t} P a_{t}\right)$ at least one of the elements of Eq. 26 is satisfied (Dagdeviren, 2008):

$$
\begin{aligned}
& \text { at } P \text { at' if }: \Phi^{+}(a t)>\Phi^{+}\left(a t^{\prime}\right) \text { and } \Phi^{-}(a t)<\Phi^{-}\left(a t^{\prime}\right) \text { or } \\
& \qquad \begin{array}{|}
\Phi^{+}(a t)>\Phi^{+}\left(a t^{\prime}\right) \text { and } \Phi^{-}(a t)=\Phi^{-}\left(a t^{\prime}\right) \text { or } \\
\Phi^{+}(a t)=\Phi^{+}\left(a t^{\prime}\right) \text { and } \Phi^{-}(a t)<\Phi^{-}\left(a t^{\prime}\right)
\end{array}
\end{aligned}
$$

PROMETHEE I evaluation allows indifference and incomparability situations. Therefore, sometimes partial rankings can be obtained. In the indifference situation $\left(a_{t} I a_{t}\right)$, two alternatives $a_{t}$ and $a_{t}$, have the same leaving and entering flows (Dagdeviren, 2008; Tuzkaya, 2009):

$$
a_{t} I \text { at' if }: \Phi^{+}\left(a_{t}\right)=\Phi^{+}\left(a_{t^{\prime}}\right) \text { and } \Phi^{-}\left(a_{t}\right)=\Phi^{-}\left(a t^{\prime}\right)
$$

Two alternatives are considered incomparable, $a_{t} R a_{t}$, if alternative $a_{t}$ is better than alternative $a_{t}$, in terms of leaving flow, while the entering flows indicate the reverse (Dagdeviren, 2008):

$$
\begin{gathered}
a_{t} R a_{t^{\prime}} \text { if : } \Phi^{+}\left(a_{t}\right)>\Phi^{+}\left(a_{t^{\prime}}\right) \text { and } \Phi^{-}\left(a_{t}\right)>\Phi^{-}\left(a_{t^{\prime}}\right) \text { or } \\
\qquad \Phi^{+}\left(a_{t}\right)<\Phi^{+}\left(a_{t^{\prime}}\right) \text { and } \Phi^{-}\left(a_{t}\right)<\Phi^{-}\left(a t^{\prime}\right)
\end{gathered}
$$

Via PROMETHE II, the complete ranking can be obtained. For the complete ranking calculations, net flow values of alternatives can be calculated as Eq. 30 . Here, if alternative $a$,'s net flow is bigger than alternative $a_{t}$ 's net flow, this indicates that, alternative $a_{t}$ outranks alternative $a_{t}$.

$\Phi^{n e t}(a t)=\Phi^{+}(a t)-\Phi^{-}(a t)$

In this study, the F-PROMETHEE technique is preferred because of the fuzzy nature of the decision problem. In the literature, there are a few studies using F-PROMETHEE approach. Bilsel et al. (2006), Chou et al. (2007), Geldermann et al. (2000) and Goumas and Lygerou (2000) have used F-PROMETHEE previously.

In the F-PROMETHEE, the main problem arises in comparing two fuzzy numbers and the index, which corresponds to a weighted average of the fuzzy numbers, proposed from Yager (1981) is found a useful way to compare fuzzy numbers. It is determined by the center of weight of the surface representing its membership function (Bilsel et al., 2006; Goumas and Lygerou, 2000). Based on the Yager's index (Yager, 1981), a triangular fuzzy number's magnitude is the value corresponding to the center of the triangle and can be expressed as in Eq. (23). The representation of a TFN here, $\tilde{F}=(n, a, b)$, is a different version of the representation used in Fuzzy Sets, ANP and F-ANP sections. This is equivalent to the previous representation by $\tilde{F}=(n-a, n, n+b)$. The following fuzzy PROMETHEE formulas are based on the representation of TFN as $(n, a, b)$.

In this study, PROMETHEE's linear preference function with indifference and strict preference is preferred for each criterion by DMT (Decision Making Team). In this preference function, two thresholds, $q$ and $p$ are needed to be determined (Fig. 1). When using the fuzzy numbers in PROMETHEE, the evaluation function explained in Fig. 1, can be converted to Eq. (31).

$$
\operatorname{Pj}\left(a t, a t^{\prime}\right)=\left\{\begin{array}{l}
0, \text { if } n-a \leq q(\text { indifference }) \\
\frac{(n, a, b)-q}{p-q}, \text { if } q \leq(n-a) \text { and }(n+b) \leq p \\
1, \text { if } n+b>p(\text { strict preference })
\end{array}\right.
$$

In Eq. 31, $q$ and $p$ values are crisp numbers and the membership functions of the fuzzy number, $C\left(a_{t}\right.$, $\left.a_{t}\right)=(n, a, b)$, is adjusted accordingly so that $n-a>=0$ and $n+b<=1$. In the if-statement in Eq. 31, the controls are the TFNs which represents the differences between $a_{t}, a_{t}$. Similarly to the PROMETHEE approach, the 


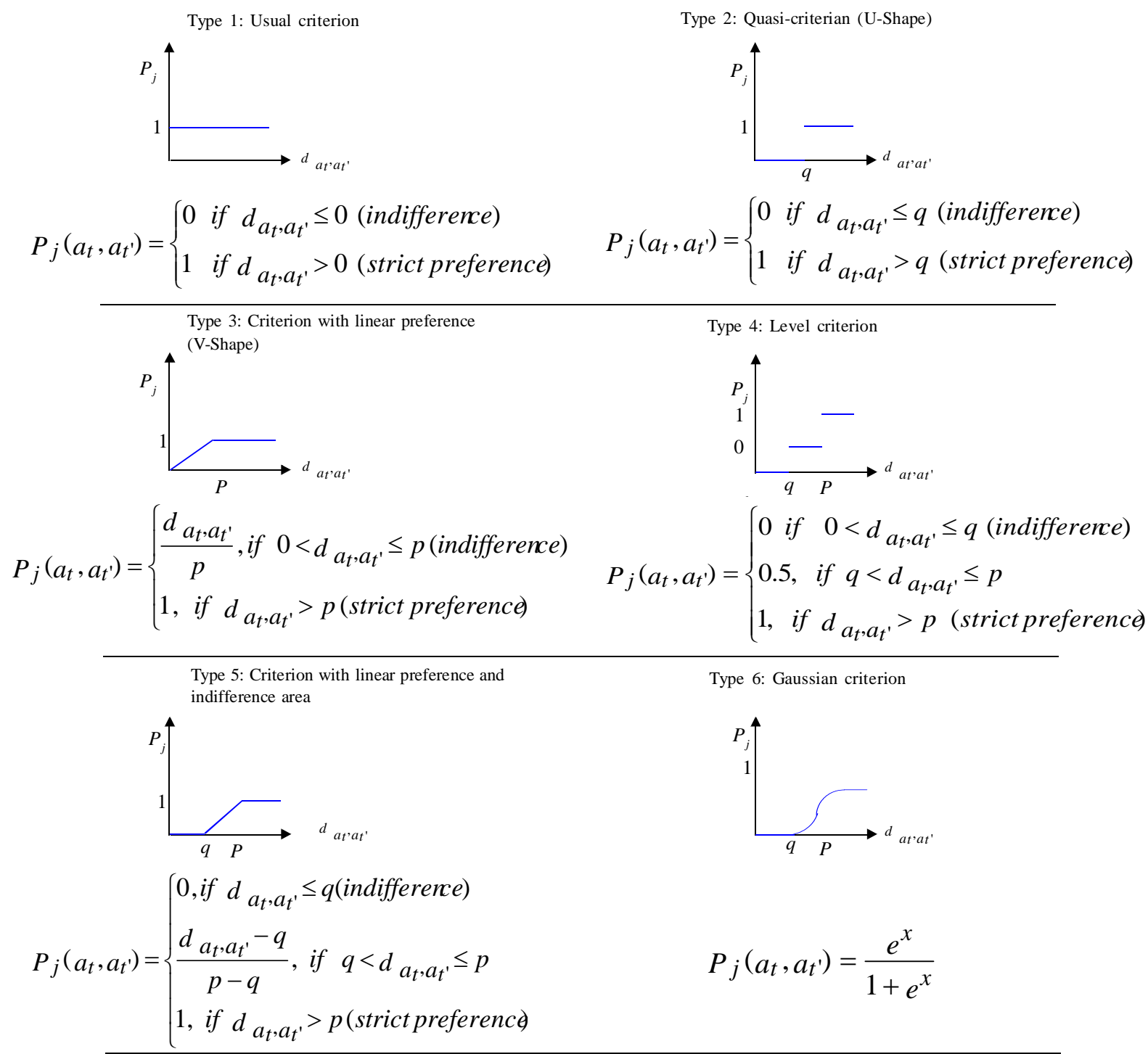

Fig. 1: PROMETHEE generalized preference functions (Brans, 1986; Tuzkaya, 2009; Vego et al., 2008)

leaving flow, the entering flow and the net flow notions are valid in the case of F-PROMETHEE (Bilsel et al., 2006). Outside of the abovementioned differences, FPROMETHEE utilizes from the PROMETHEE's application steps. In these steps, for the operations with fuzzy numbers, the basic operators given in the "Fuzzy sets" section can also be used.

A hybrid fuzzy multi-criteria decision methodology for evaluation of suppliers with the environmental criteria

In this study, a novel methodology that integrates F-ANP and F-PROMETHEE approaches is proposed. F-ANP is utilized for the evaluation of decision criteria. The usage of ANP integrates the interdependence between criteria into the decisionmaking process. On the other hand, the vagueness in the decision process is reflected via the usage of fuzzy sets. Because the steps of ANP are time consuming and complicated, F-ANP is utilized only in the decision criteria evaluation phase and the rest of the calculations are completed via FPROMETHEE approach. Fig. 2 shows the details of the proposed methodology. In the F-ANP, the decision-making team (DMT) are asked to compare the criteria considering the effects on achieving 


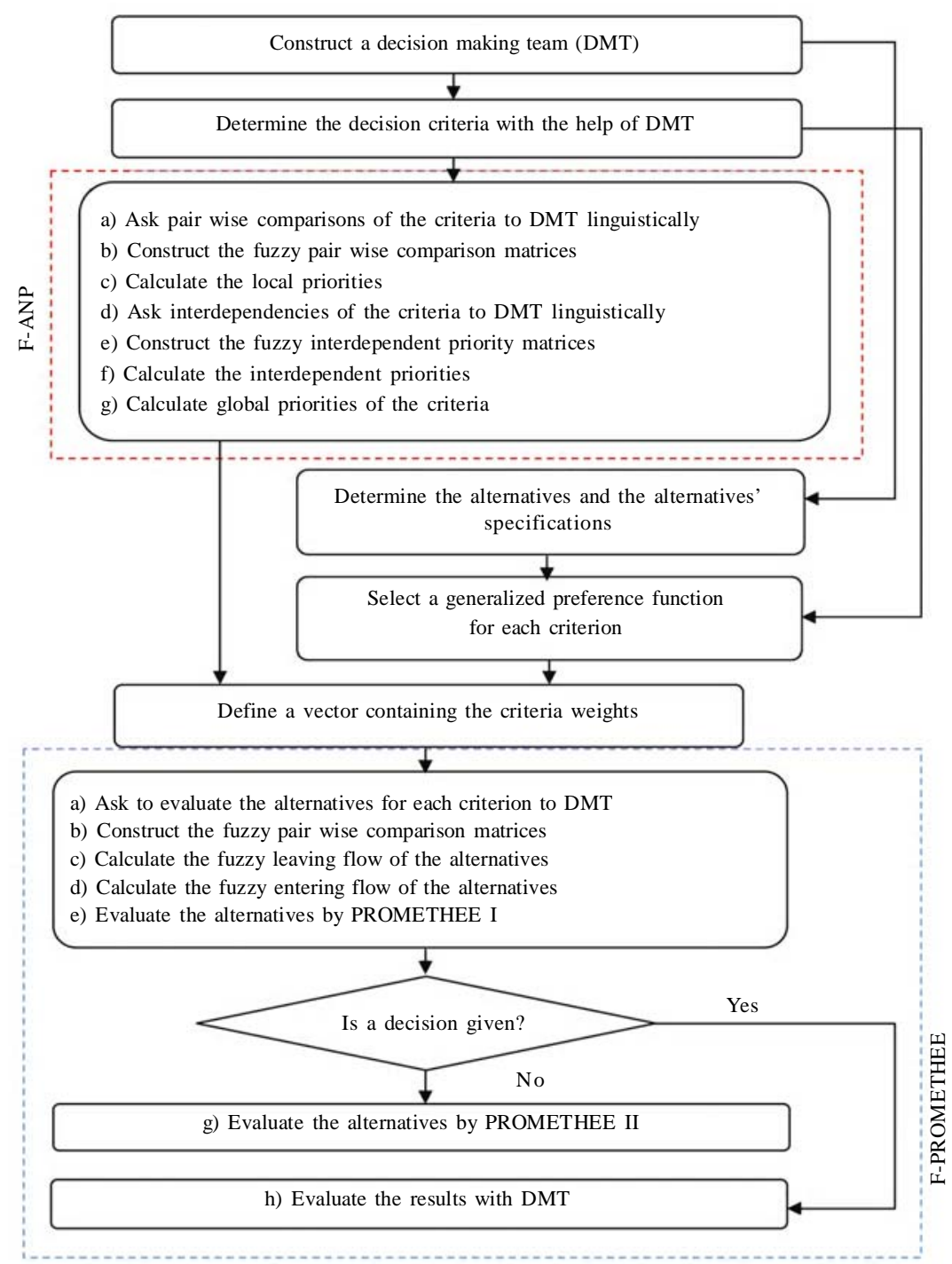

Fig. 2: The integrated F-ANP and F-PROMETHEE methodology

Table 1: Linguistic scale for importance used for ANP comparisons (Kahraman et al., 2006)

\begin{tabular}{lr}
\hline Linguistic scale for importance & Triangular fuzzy scale \\
\hline Just equal & $(1,1,1)$ \\
Equally important (EI) & $(0.5,1,1.5)$ \\
Weakly more important (WMI) & $(1,1.5,2)$ \\
Strongly more important (SMI) & $(1.5,2,2.5)$ \\
Very strongly more important (VSMI) & $(2,2.5,3)$ \\
Absolutely more important (AMI) & $(2.5,3,3.5)$ \\
\hline
\end{tabular}

main goal and asked to compare criteria considering the effects on the other criteria. In this process, the used linguistic scale for relative importance (RI) is given in Table 1.
Table 2: Linguistic scale for importance used for PROMETHEE evaluations (Bilsel et al., 2006)

\begin{tabular}{lr}
\hline Linguistic scale for evaluation & Triangular fuzzy scale \\
\hline Strongly disagree (SDA) & $(0,0,0.15)$ \\
Disagree (DA) & $(0,0.15,0.30)$ \\
Little disagree (LDA) & $(0.15,0.30,0.50)$ \\
No comment (NC) & $(0.30,0.50,0.65)$ \\
Little agree (LA) & $(0.50,0.65,0.80)$ \\
Agree (A) & $(0.65,0.80,1)$ \\
Strongly agree (SA) & $(0.80,1,1)$ \\
\hline
\end{tabular}

In the F-PROMETHEE phase, the DMT is asked to evaluate alternatives considering each criterion. For this evaluation stage, the used linguistic scale for relative importance is given in Table 2 . 


\section{RESULTS AND DISCUSSION}

Application of proposed approach: A Case study for environmental performance evaluation of a white goods manufacturer's suppliers

To foster the better understanding and the validation of the proposed methodology, a real life case study from a white goods manufacturer of Turkey is presented. This firm has selected because of its field of activity. White goods sector is one of the important industrialized sectors in Turkey which consists of ten major and about a hundred SMEs as producers and twenty importer firms. It has enormous production capacity with a significant acceleration (Eroglu and Özdamar, 2006). Adaptation of the sector to the EU regulations has increased the international competence. However, during the adaptation continuum, environmental regulations related to the sector bring difficulties in the application. For elimination of these difficulties, there is a need for determining shortages and setting measurements for tracking improvements. To this end, first of all environmental measurements for the evaluation and monitoring of supply chains processes environmental performance should be structured. Considering this situation, in this study, the proposed approach is applied in a systematic way to a firm from Turkish White Goods Industry and interviews are realized from experts of this sector in each phase.

As a first step of the application, a decision-making team (DMT) is constructed for the decision process. The DMT is constituted from three academicians, Manager of purchasing department and his team consisted of eight purchasing specialist. After completing this phase, criteria are determined by interview sessions done with DMT and considering the related literature conducted before (especially it has been referred to the studies prepared by Lee et al. (2009), Lu et al. (2007), Nakashima et al. (2006), Tsoulfas and Pappis (2006), Tsoulfas and Pappis (2008)). For elimination of criteria the decision making team had a final meeting with the participation of sales manager, public relationships manager and franchising network responsible.

The main criteria could be summarized as; Green Process Management (GPM), Green Product (GP), Green Image (GI), Environment and Legislative Management (ELM), Pollution Control (PC), Environmental Costs (EC).
GPM criteria cluster contains the processes, related to the production, from R\&D efforts, product design, technology, planning and monitoring and distribution phases of production and issues related to environmental and pollution performances of first and second tier of suppliers. GP main criteria cluster gathers issues related with the product characteristics that provides opportunity to recyclability, reusability, and re-manufacturability etc activities. Here, the ability of the contribution of the suppliers' to the green features of the product arise from components and materials supplied is examined. GI main criteria cluster is related with the environmental image of the suppliers and contains issues such as social responsibility efforts, activities to motivate customer for consuming green products, training and programs for employees for green consciousness, voluntarily involvement to the legislative regulations of government by firm. ELM main criteria cluster is related with the legislative and managerial activities of the suppliers. These activities may contain environment-related certificates (ISO 14000, WEEE etc.) and reverse logistics (RL) management programs. $P C$ main criteria cluster is related with the pollution factors constituted from the supplier production and service processes and product components. These factors are related with the air emissions, wastewater, solid wastes, energy consumption, use of harmful materials and hazardous wastes. EC main criteria cluster contains cost factors related with the environmental and green production, logistics and other activities.

Interdependencies between main criteria clusters are given in Fig. 3. These relations can be summarized as follows: GPM cluster has influence on the GPM, GP, ELM, PC, EC and GI criteria clusters. As an example, $R \& D$ projects for green production sub-criterion of GPM has influence on design for the environment, green production technology, green distribution, second tier supplier environmental evaluation and secondary market for waste generated sub-criterion of same cluster, GPM. Same sub-criterion also has influence on all sub-criteria of the GP, ELM and PC criteria clusters. But, it influences only cost of producing green products and cost of RL about green products sub-criteria of EC criteria cluster. The reason that all the sub-criteria in the main criteria clusters do not influence each other could be explained as follows. For example, R\&D projects for the green production sub-criterion could decrease cost of producing green 


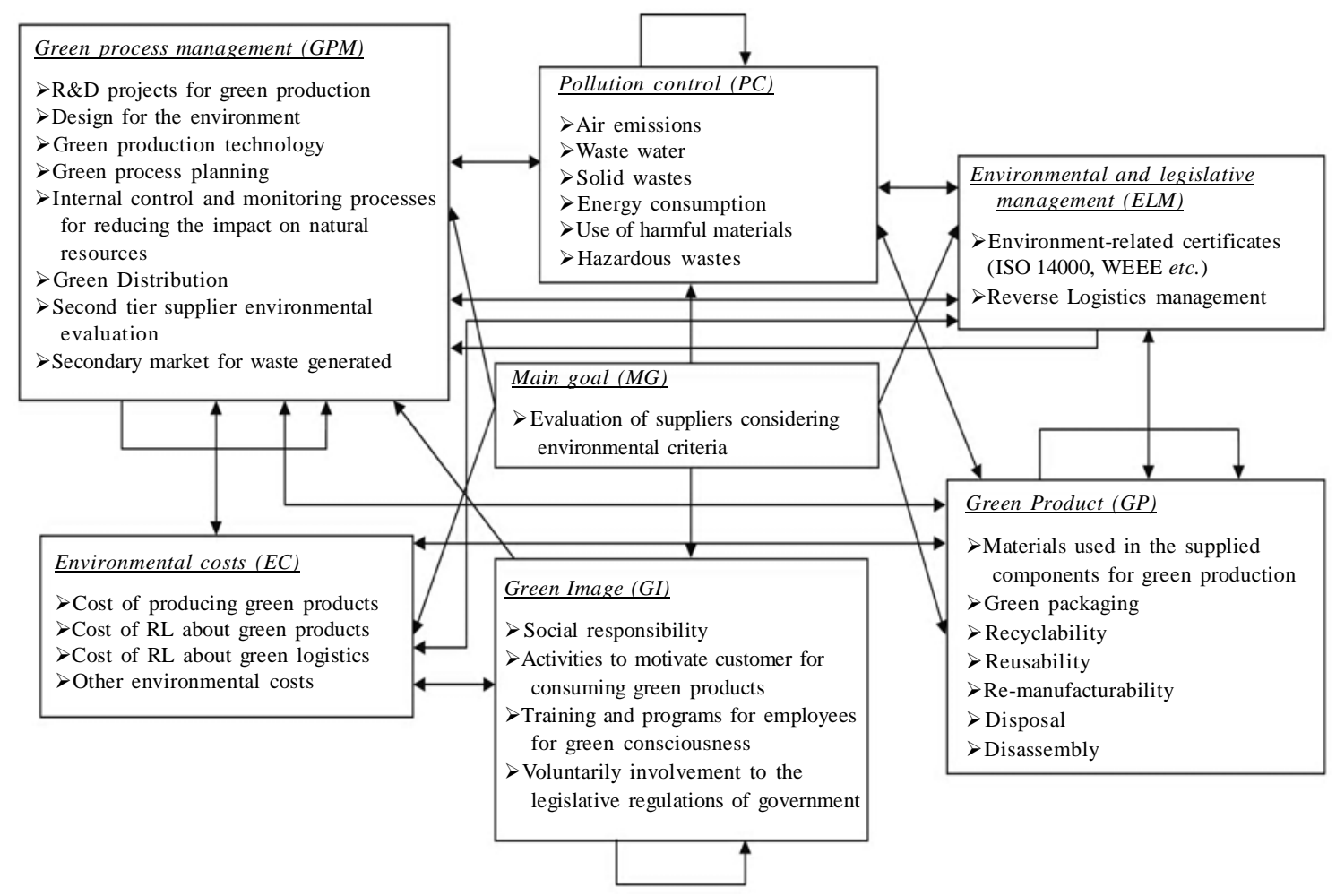

Fig. 3: Suppliers' environmental evaluation criteria and the criteria influences

Table 3: Linguistic criteria comparisons considering the impact of the main goal (MG)

\begin{tabular}{lllllll}
\hline MG & GPM & GP & GI & ELM & PC & EC \\
\hline GPM & JE & WMI & SMI & WMI & SLI & WMI \\
GP & WLI & JE & SMI & WMI & EI & WMI \\
GI & SLI & SLI & JE & SLI & WLI & ALI \\
ELM & WLI & WLI & SMI & JE & SLI & WLI \\
PC & SMI & EI & WMI & SMI & JE & WMI \\
EC & WLI & WLI & AMI & WMI & WLI & JE \\
\hline
\end{tabular}

products and cost of RL about green products subcriteria of EC. Because with an effective R\&D performance, the right ways of producing green product with low or optimum cost could be explored. Also the green distribution sub-criterion of GPM has a direct effect on air emission sub-criterion of PC, because more environmental friendly distribution alternatives may decrease the harmful emissions to the atmosphere. All other interdependencies could be seen in Fig. 3.

In the first step of the fuzzy-ANP approach, the DMT is asked to compare the decision criteria linguistically according to their affect on the realization of the main goal $(M G)$. Here, it is assumed that there are no interdependencies between criteria and the scale in
Table 4: Alternatives linguistic evaluations by DMT

\begin{tabular}{lllllll}
\hline & GPM & GP & GI & ELM & PC & EC \\
\hline$A_{1}$ & A & LA & LA & NC & LA & LDA \\
$A_{2}$ & SDA & DA & SDA & SDA & SDA & A \\
$A_{3}$ & NC & NC & LA & NC & LDA & A \\
$A_{4}$ & LA & A & LA & NC & NC & A \\
$A_{5}$ & LA & LA & A & LDA & LDA & LA \\
\hline
\end{tabular}

Table 1 is utilized. Table 3 shows the DMT pair-wise comparisons.

Then, the linguistic preferences of the DMT are converted to triangular fuzzy numbers utilizing from Table 1. At the next step, using logarithmic least-square technique (Eq. 9) and normalization, criteria weights are calculated with the assumption of there is no interdependence between them as $(0.15,0.19,0.25)$, $(0.14,0.19,0.25),(0.07,0.09,0.11),(0.10,0.13,0.17),(0.16$, $0.23,0.29)$ and $(0.13,0.17,0.22)$ for GPM, GP, GI, ELM, PC and EC, respectively.

Then the affects of each criterion on the other criteria are analyzed using same steps with the comparison of the decision criteria linguistically according to their affects on the realization of the main goal. For this stage, 
Int. J. Environ. Sci. Tech., 6 (3), 477-490, Summer 2009
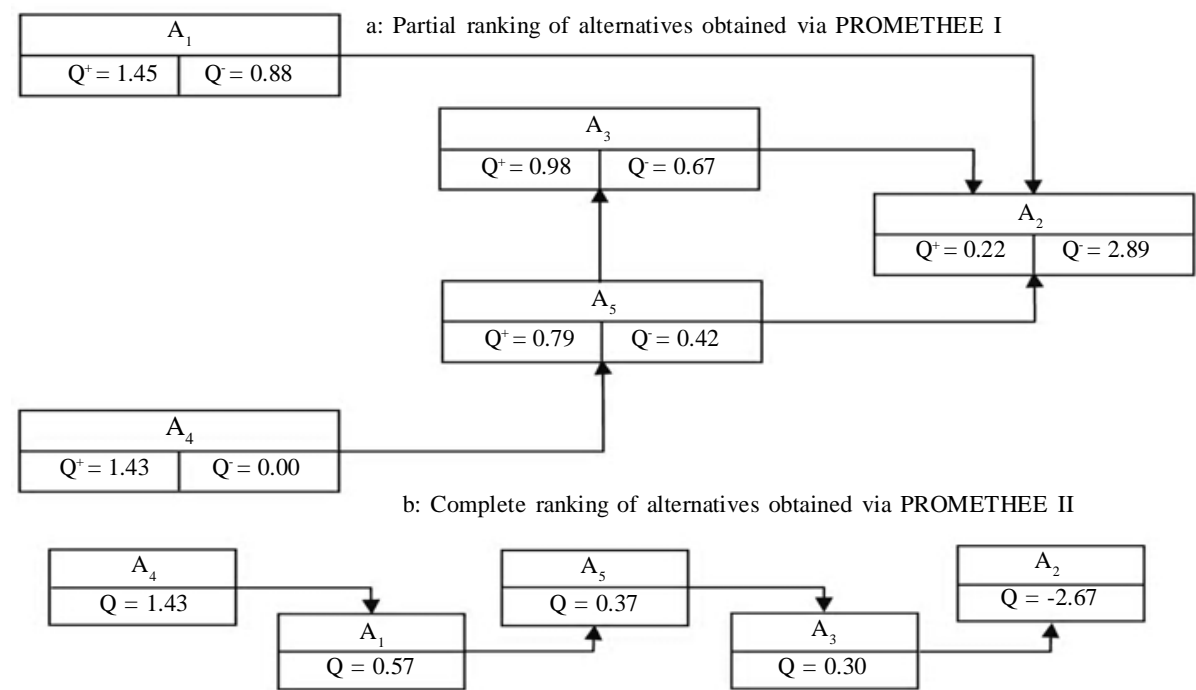

Fig. 4: Ranking results via PROMETHEE I and PROMETHEE II

the DMT is asked to "compare the effects of $C_{x}$ and $C_{y}$ on $C_{z}$ ” for each criteria pair”.

At the last step of F-ANP, using 11.

logarithmic least-square technique (Eq. 9) and Chang's extent analysis, the weights of the criteria is calculated. According to the results, the weights of the GPM, GP, GI, ELM, EC and $P C$ are 0.25, 0.21, 0.03, 0.07, 0.21 and 0.22, respectively. The weight vector is also calculated using COA method and Yagerindex. With these methods, very similar results are obtained. Following the F-ANP calculations, using the criteria weights, F-PROMETHEE calculations are realized. As a first step of F-PROMETHEE, the DMT is asked to determine the generalized criterion type of each criterion and $q, p$ values. Generalized criterion type is selected as level criterion type for each and $q, p$ values are determined as " 0 and 0.6 ", respectively. Following this step, the DMT is asked to evaluate the alternatives linguistically (Table 4) and then the linguistic evaluations are converted to triangular fuzzy numbers utilizing from Table 2. At the next step, the differences between each alternative pair for each criterion are calculated. Using these differences, Yager index values (Eq. 23) and criteria weights, alternatives' leaving, entering and net flows are calculated (Table 5) utilizing from Eq. (24-31). Then, partial ranking of alternatives are found via PROMETHEE I (Fig. 4a). Based on this partial ranking, $A_{1}$ and $A_{4}$ alternatives outrank all the other alternatives and $\mathrm{A} 2$ is outranked by all the other alternatives. However, $A_{1}$ and $A_{4}$ cannot be compared with each other, since, $A_{1}$ 's $\phi^{+}$is bigger than $A_{4}$, but, $A_{1}$ 's $\phi$ - is bigger than $A_{4}$, too. This situation causes a need to
Table 5: Alternatives' leaving, entering and net flows

\begin{tabular}{lllllllr}
\hline & $\mathrm{A}_{1}$ & $\mathrm{~A}_{2}$ & $\mathrm{~A}_{3}$ & $\mathrm{~A}_{4}$ & $\mathrm{~A}_{5}$ & $\Phi^{+}$ & \multicolumn{1}{c}{$\Phi^{\text {net }}$} \\
\hline $\mathrm{A}_{1}$ & 0,00 & 0,78 & 0,46 & 0,00 & 0,21 & 1,45 & 0,57 \\
$\mathrm{~A}_{2}$ & 0,22 & 0,00 & 0,00 & 0,00 & 0,00 & 0,22 & $-2,67$ \\
$\mathrm{~A}_{3}$ & 0,22 & 0,76 & 0,00 & 0,00 & 0,00 & 0,98 & 0,30 \\
$\mathrm{~A}_{4}$ & 0,22 & 0,78 & 0,21 & 0,00 & 0,21 & 1,43 & 1,43 \\
$\mathrm{~A}_{5}$ & 0,22 & 0,57 & 0,00 & 0,00 & 0,00 & 0,79 & 0,37 \\
$\Phi^{-}$ & 0,88 & 2,89 & 0,67 & 0,00 & 0,42 & & \\
\hline
\end{tabular}

utilize from PROMETHEE-II technique for a complete ranking of alternatives. At the last step of calculations, the complete ranking of alternatives is determined (Fig. 4b). Based on the PROMETHEE II calculations, $A_{4}$ is the best, $A_{2}$ is the worst alternative. While in PROMETHEE I, $A_{1}$ and $A_{4}$ cannot be compared, according to PROMETHEE II, it can be seen that $\mathrm{A}_{4}$ is better than $\mathrm{A}_{1}$.

Analyzing the results and sensitivity analyses

As can be seen and explained from the previous section, $A_{4}$ is superior to the other alternatives. $A_{4}$ 's superiority comes from some reasons, such as: $A_{4}$ is at least equal to the other alternatives for the criteria $G P$, ELM, $P C$ and EC. Within these criteria, GP, EC and PC have relatively high weighting values. Altough, $A_{4}$ is not superior to all the others in terms of the most important criteria, GPM, it's superiority is for the closer weighted criteria to the GPM (GP, EC and $P C$ ) can tolerate this situation. The least preferred alternative, $A_{2}$, is the worst alternative for all criteria except $E C$ criterion.

According the results that obtained with PROMETHEE I, $A_{1}$ and $A_{4}$ cannot be compared. The reason of this situation is that, $A_{1}$ is superior to $A_{4}$ in the leaving flow 


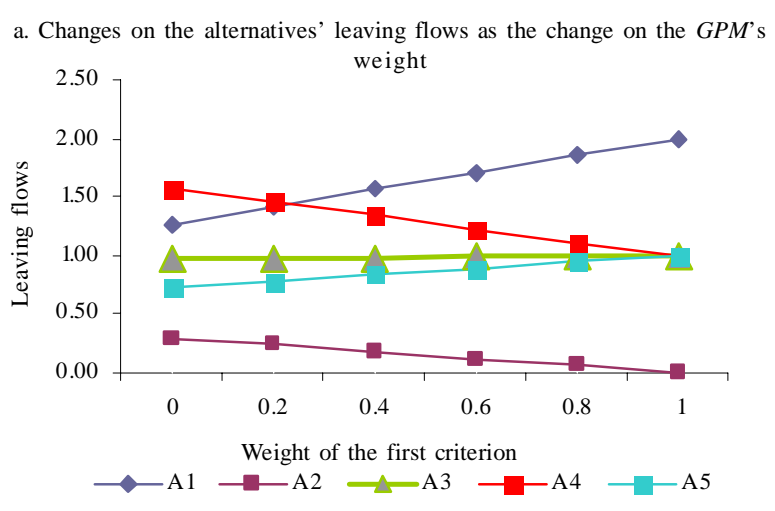

b. Changes on the alternatives' entering flows as the change on the

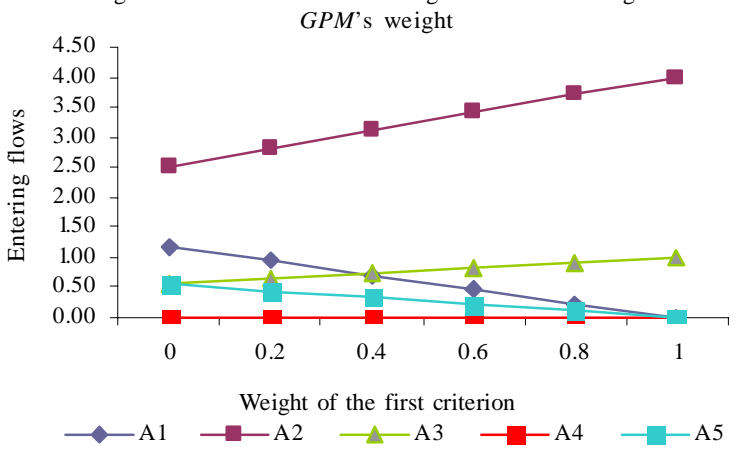

c. Changes on the alternatives' net flows as the change on the GPM's

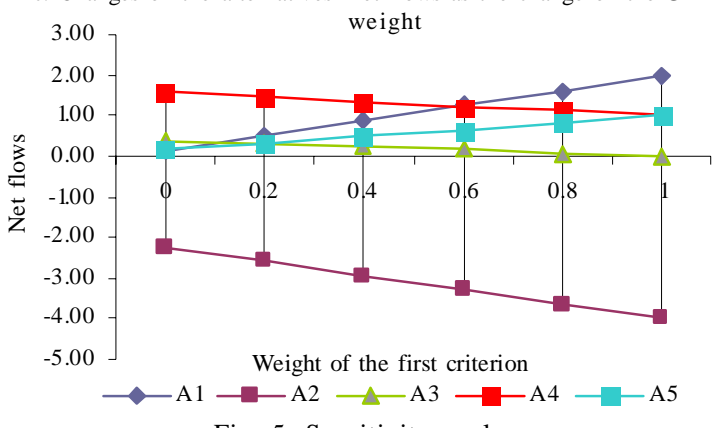

Fig. 5: Sensitivity analyses

comparison, but, $A_{4}$ is superior to $A_{1}$ in the entering flow comparison. To compare these two alternatives, the net flow should be calculated in PROMETHEE II and with PROMETHEE II complete ranking comparisons, it can be concluded that $A_{4}$ is superior to $A_{1}$.

As mentioned before, the weights of the decision criteria are determined via F-ANP. In this stage, the sensitivity of the results to the changes in the criteria weights is analyzed. As an example for all other sensitivity analysis of criteria weights, here, only the results sensitivity to GPM weights is presented
(Fig. 5). From Fig. 5a, changes on the alternatives' leaving flows as the change on the GPM weight can be seen. With the increase in the weight of the GPM from zero to one, the leaving flow values of $\mathrm{A}_{2}$ and $\mathrm{A}_{4}$ are getting worse. The reason of $A_{2}$ is getting worse is that this alternative has not a good evaluation for the criterion GPM. On the other hand, $\mathrm{A}_{4}$ 'sevaluation for this criterion is not a worse evaluation. The reason of the decrease in the $A_{4}$ 's situation is that this alternative is better for the other criteria, but, with the increase of weight of GPM, the relative importance of the others decreases. $A_{1}$ has the best evaluation for the criterion GPM's and this results with a significant increase of the leaving flow of it with the increase of the GPM's weight. Fig. 5b shows the changes on the alternatives entering flows as the change on the GPM weight. Alternative $A_{2}$ and $A_{3}$ 's entering flows are getting worse with the increase of the GPM weight. This is because, these two alternatives have worse linguistic evaluations $\left(A_{2}\right.$ and $A_{3}$ 's evaluations are SDA and NC, respectively) for the criterion GPM. When considering the net flows (Fig. 5c), with the increase of the GPM's weight, the net flows of $\mathrm{A}_{1}$ and $A_{5}$ are getting better and the situations of the others are getting worse. Since, net flow is the difference between leaving and entering flow, similar interpretations can be made for the Fig. 5c. With the increase of GPM's weight and decrease of the others relative weights, the situation of $A_{1}$ and $A_{5}$ are getting better, because, $A_{1}$ takes the best evaluation value for this criterion and $A_{5}$ takes its best evaluation value between higher weighted criteria. In spite of the fact that $A_{5}$ is a good linguistic evaluation for the criterion GI (A), the decrease of this criterion weight does not affect the situation because of its lower weight.

As a final stage, these results are proposed to the DMT. According to their investigations on the results, the environmental evaluations of the suppliers are found to be realistic and applicable as a part of their supplier evaluation procedure. This situation increases the reliability of the proposed approach. Also, when considering the application phase, proposed approach proves its effectiveness and easiness to apply. Expert opinions are reflected to the procedure in a user friendly way and also results are sensitive to the change in the parameters which is an indicator that proposed methodology may be a generally accepted methodology for the other sector applications. 


\section{CONCLUSION}

In this study, an integrated fuzzy multi-criteria decision-making methodology is utilized. This is a novel methodology both for the multi-criteria decisionmaking literature and the suppliers' evaluation literature. Also, there is not too much study for the supplier environmental evaluation literature. This study is unique between these limited number of the study with the evaluation process, especially with the consideration of criteria influences and the vagueness of the decision process. Also, this is the first study that integrates the fuzzy-ANP and fuzzy-PROMETHEE approaches.

The proposed methodology has some advantages comparing the previously proposed methodologies which are proved with a real life case study from Turkish White Goods Industry. First of all, the vagueness embedded in this decision-making area may easily incorporated into the decision-making process with this methodology. Also, the DMT is not asked to give accurate values for the evaluations. Contrarily, both the criteria evaluations and the alternative evaluations are started with the linguistic preferences. This situation increases the usefulness and easiness of the methodology. Another advantage of the proposed methodology comes from a property of ANP. This property is the ANP's superiority that reflects the interdependencies into the decision-making process. Thanks to this property, the interdependencies among the evaluation criteria could be inserted the decision making process. Besides, PROMETHEE's easiness in calculation and application phases is a major advantage of the proposed methodology. For the future studies, the usage of this approach in different application areas may be considered, especially in the application areas that the vagueness is a specification of them.

\section{REFERENCES}

Albadvi, A.; Chaharsooghi, S. K.; Esfahanipour, A., (2007). Decision making in stock trading: An application of PROMETHEE. Eur. J. Oper. Res., 177 (2), 673-683 (11 pages).

Ayag, Z.; Ozdemir, R. G., (2006). A fuzzy AHP approach to evaluating machine tools alternatives. J. Intell. Manuf., 17 (2), 179-190 (12 pages).

Bilsel, R. U.; Buyukozkan, G.; Ruan, D., (2006). A fuzzy preference-ranking model for a quality evaluation of hospital web sites. Int. J. Intell. Syst., 21 (3), 1181-1197 (17 pages).

Brans, J. P.; Vincle, P., (1985). A preference ranking organization method. Manag. Sci., 31 (6), 647-656 (12 pages).
Brans, J. P.; Vincle, P.; Mareschal, B., (1986). How to select and how to rank projects: The PROMETHEE method. Eur. J. Oper. Res., 24 (2), 228-238 (11 pages).

Büyükozkan, G.; Ertay, T.; Kahraman, C.; Ruan, D., (2004). Determining the importance weights for the design requirements in the house of quality using the fuzzy analytic network approach. Int. J. Intell. Syst., 19 (5), 443-461 (19 pages).

Chang, D. Y., (1996). Application of the extent analysis method on fuzzy AHP. Eur. J. Oper. Res., 95 (3), 649-655 (7 pages).

Chen, C. T., (2001). A fuzzy approach to select the location of the distribution center. Fuzzy Set. Syst., 118 (1), 65-73 (9pages).

Chou, W. C.; Lin, W. T.; Lin, C. Y., (2007). Application of fuzzy theory and PROMETHEE technique to evaluate suitable ecotechnology method: A case study in Shismen Reservoir Watershed, Taiwan. Ecol. Eng., 31 (4), 269-280 (12 pages).

Dagdeviren, M., (2008). Decision making in equipment selection: An integrated approach with AHP and PROMETHEE. J. Intell. Manuf., 19 (4), 397-406 (10 pages).

Eroglu, O.; Özdamar, G., (2006). Competitiveness of the Turkish manufacturing industry and a study on the household appliances industry. Akdeniz I.I.B.F. J., 11, 85104 (20 pages).

Geldermann, J.; Spengler, T.; Rentz, O., (2000). Fuzzy outranking for environmental assessment. Case study: Iron and steel making industry. Fuzzy Set. Syst., 115 (1), 45-65 (21 pages).

Goumas, M.; Lygerou, V., (2000). An extension of the PROMETHEE method for decision making in fuzzy environment: Ranking of alternative energy exploitation projects. Eur. J. Oper. Res., 123 (3), 606-613 (8 pages).

Handfield, R. B.; Nichols, E. L.; (2004). Key issues in global supply base management. Ind. Market. Manag., 33 (1), 29-35 (7 pages).

Handfield, R.; Walton, S. V.; Sroufe, R.; Melnyk, S. A., (2002). Applying environmental criteria to supplier assessment: A study in the application of the analytical hierarchy process. Eur. J. Oper. Res., 141 (1), 70-87 (18 pages).

Humphreys, P. K.; Wong, Y. K.; Chan, F. T. S., (2003). Integrating environmental criteria into the supplier selection process. J. Mater. Process. Tech., 138 (1), 349356 (8 pages).

Jharkharia, S.; Shankar, R., (2007). Selection of logistics service providers: An analytic network process (ANP) approach. Omega, 35 (3), 274-289 (16 pages).

Kahraman, C.; Ertay, T.; Büyüközkan, G., (2006). A fuzzy optimization model for QFD planning process using analytic network approach. Eur. J. Oper. Res., 171 (2), 390-411 (22 pages).

Lamming, R.; Hampson, J., (1996). The environment as a supply chain management issue. Brit. J. Manag., 7, 45-62 (18 pages).

Lee, A. H. I.; Kang, H. Y.; Hsu, C. F.; Hung, H. C., (2009). A green supplier selection model for high-tech industry. Expert Syst. Appl., 36 (4), 7917-7927 (11 pages). 
Lin, R. H., (2009). An integrated FANP-MOLP for supplier evaluation and order allocation. Appl. Math. Model., 33 (6), 2730-2736 (7 pages).

Lu, L. Y. Y.; Wu, C. H.; Kuo, T. C., (2007). Environmental principles applicable to green supplier evaluation by using multi-objective descision analysis. Int. J. Prod. Res., 45 (18-19), 4317-4331 (15 pages).

Macharis, C.; Springael, J.; De Brucker, K.; Verbeke, A., (2004). PROMETHEE and AHP: The design of operational synergies in multi-criteria analysis. Strengthening PROMETHEE with ideas of AHP. Eur. J. Oper. Res., 153 (2), 307-317 (11 pagrs).

Nakashima, K.; Nose, T.; Kuriyama, S., (2006). A new approach to environmental performance evaluation. Int. J. Prod. Res., 44 (18-19), 4137-4143 (7 pages)

Noci, G., (1997). Designing "green” vendor rating systems for the assessment of a supplier's environmental performance. Eur. J. Purchasing Supply Manag., 3 (2), 103-114 (12 pages).

Ofori, G., (2000). Greening the construction supply chain in Singapore. Eur. J. Purchasing \& Supply Manag., 6 (3-4), 195-206 (12 pages).

Promentilla, M. A. B.; Furuichi, T.; Ishii, K.; Tanikawa, N., (2008). A fuzzy analytic network process for multi-criteria evaluation of contaminated site remedial countermeasures. J. Environ. Manag., 88 (3), 479-495 (17 pages).

Saaty, T. L., (1999). Fundamentals of the analytic network process. ISAHP 1999, Kobe, Japan, August 12-14.

Saaty, T. L.; Takizawa, M., (1986). Dependence/ interdependence from linear hierarchies to non-linear network. Eur. J. Oper. Res., 26, 229-237 (9 pages).

Sarkis, J., (1998). Evaluating environmentally conscious business practices. Eur. J. Oper. Res., 107 (1), 159-174 (16 pages).

Sugeno, M., (1985). An Introductory survey of fuzzy control. Inform. Sciences, 36 (1-2), 59-83 (25 pages).

Tuzkaya, G.; Gulsun, B., (2008). Evaluating centralized return centers in a reverse logistics network: An integrated fuzzy multi-criteria decision approach. Int. J. Environ. Sci. Tech., 5 (3), 339-352 (14 pages).

Tuzkaya, G.; Onut, S.; Tuzkaya, U. R.; Gülsün, B., (2008). An analytic network process approach for locating undesirable facilities: An example from Istanbul, Turkey. J. Environ. Manag., 88 (4), 970-983 (14 pages).

Tuzkaya, U. R., (2009). Evaluating the environmental effects of transportation modes using an integrated methodology and an application. Int. J. Environ. Sci. Tech., 6 (2), 277-290 (14 pages).

Tuzkaya, U. R.; Onut, S., (2008). A fuzzy analytic network process based approach to transportation-mode selection between Turkey and Germany: A case study. Inform. Sciences, 178 (15), 3133-3146 (14 pages)

Tsoulfas, G. T.; Pappis, C. P., (2006). Environmental principles applicable to supply chain design and operation. J. Clean. Prod., 14, 1593-1602 (10 pages).

Tsoulfas, G. T.; Pappis, C. P., (2008). A model for supply chains environmental performance analysis and decision making. J. Cleaner Prod., 16 (15), 16471657 (11 pages).

Ulengin, F.; Topçu Y. I.; Pahin, P. Ö., (2001). An integrated decision aid system for bosporous water-crossing problem. Eur. J. Oper. Res., 134 (1), 179-192 (14 pages).

Vego, G.; Kucar-Dragicevic, S.; Koprivanac, N., (2008). Application of multi-criteria decision-making on strategic municipal solid waste management in Dalmatia, Croatia. Waste manag., 28 (11), 2192-2201 (10 pages).

Wang, T. C.; Chang, T. H., (2007). Application of TOPSIS in evaluating initial training aircraft under a fuzzy environment. Expert Syst. Appl., 33 (4), 870-880 (11 pages).

Yager, R. R., (1981). A procedure for ordering fuzzy subsets of the unit interval. Inform. Sciences, 24 (2), 143-161 (19 pages).

Zhu, K. J.; Jing, Y.; Chang, D. Y., (1999). A Discussion on extent analysis method and applications of fuzzy AHP. Eur. J. Oper. Res., 116 (2), 450-456 (7 pages).

\footnotetext{
AUTHOR (S) BIOSKETCHES

Tuzkaya, G., Ph.D., Research assistant, Department of Industrial Engineering, Yildiz Technical University, Istanbul, Turkey.

Email:gtuzkaya@yildiz.edu.tr

Ozgen, A., Ph.D., Lecturer, Department of Industrial Engineering, Okan University, Post Doctoral student, Logistic Department of Technology and Management Faculty of Berlin Technical University, Berlin, Germany. Email: arzum.eser@okan.edu.tr

Ozgen, D., Ph.D., Research assistant. Department of Industrial Engineering, Yildiz Technical University, Istanbul, Turkey. Email: dozgen@yildiz.edu.tr

Tuzkaya, U. R., Ph.D., Assistant professor, Department of Industrial Engineering, Yildiz Technical University, Istanbul, Turkey. Email: tuzkaya@yildiz.edu.tr
} 